\title{
The 150,000-Volt Transmission Line of the Knoxville Power Company
}

\author{
BY THEODORE VARNEY \\ Aluminum Company of America, Pittsburgh, $\mathrm{Pa}$.
}

$\mathrm{A}^{\mathrm{T}}$ $\mathrm{T}$ a point on the Little Tennessee River a short distance above the mouth of the Cheoah River in North Carolina, the Knoxville Power Company has completed within the past year, the first portion of an extensive hydroelectric development. The ultimate development will require the tying together of a number of plants scattered over a large area and it was therefore necessary to choose powerhouse and transmission line equipment which would be best adapted to the entire system.

The initial development described herein might appear inconsistent if considered alone from the standpoint of voltage and length of line, but when regarded as an integral part of the larger scheme its characteristics become rational. For instance, the present line crosses a mountainous country, broken by river valleys and steep cliffs for about half its length, while the remaining distance lies over a fairly level plain. The rough ground necessitating a minimum number of supports required that a maximum amount of power be carried by each circuit and this in general means a high transmission voltage. It is probable that in choosing between a voltage of 110,000 and 150,000 the former would have sufficed for the present line, but as the complete development will involve lines of greater length, the higher voltage would have later become necessary and a uniform voltage for the system was considered essential.

Another point taken into account by the engineers who were responsible for the present design was that the trend or development is toward the use of higher voltages for transmission lines.

Still another consideration which made it advisable to provide for high efficiency, and consequently small losses, is the high load factor of the electrolytic process for which the system is primarily designed. Power for this purpose is valuable and interruptions are very expensive.

The electrolytic plant is located at Alcoa, Tennessee, formerly known as North Maryville, and its distance along the line from the present power house at Cheoah is 24.3 miles. At present one line only is completed between these points but ultimately another parallel line will be provided, and these will later be joined by additional lines supplied from other plants.

The broad scheme of development contemplated for the entire system is to operate it normally in units of about $50,000 \mathrm{~h}$. p. so that the interruption due to a short circuit or other trouble anywhere on the system will not cause any disturbance or interruption outside of this group of $50,000 \mathrm{~h} . \mathrm{p}$. With this idea in view, the power houses contain no low-tension buses. Each of the generators (most of which will be about 20,000 kv-a. capacity) is served by a bank of transformers connected directly to it through low-tension switches, the hightension side of the bank of transformers being connected to the high-tension bus through a set of oil switches. The high-tension bus at the powerhouses is sectionalized in such a manner that in normal operation a group of two of these generators with their transformer banks is connected to it and this group serves a transmission line, which terminates in a section of high-tension bus at the receiving end at Alcoa, which through step-down

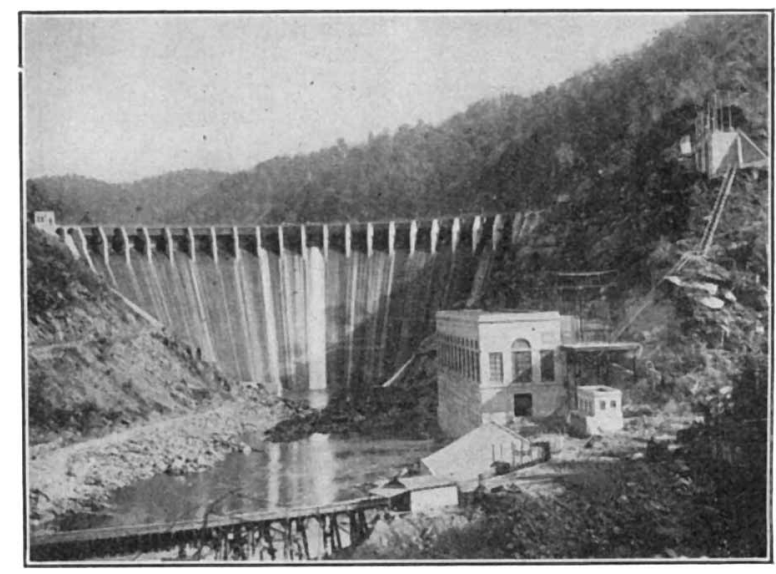

Dam and Power House at Cheoah

transformers, serves an electrolytic load of about $50,000 \mathrm{~h}$. p. The high-tension buses at the generating station and the high-tension buses at the receiving station are so arranged that they can be interconnected whenever emergency makes it necessary to run them in multiple, but it is intended that in normal operation the system shall be operated in units of about 50,000 h. p. consisting of a suitable amount of generating capacity and step-up transformers delivering power over an individual circuit to a suitable sectionalized load at the receiving end.

The right-of-way at the Alcoa end is $385 \mathrm{ft}$. wide and provides for four double-circuit tower lines. As the rough country is approached some of the lines branch off and the right-of-way narrows to $340 \mathrm{ft}$. to accommodate four single-circuit tower lines while still further along, the width is decreased to $200 \mathrm{ft}$. for the two 

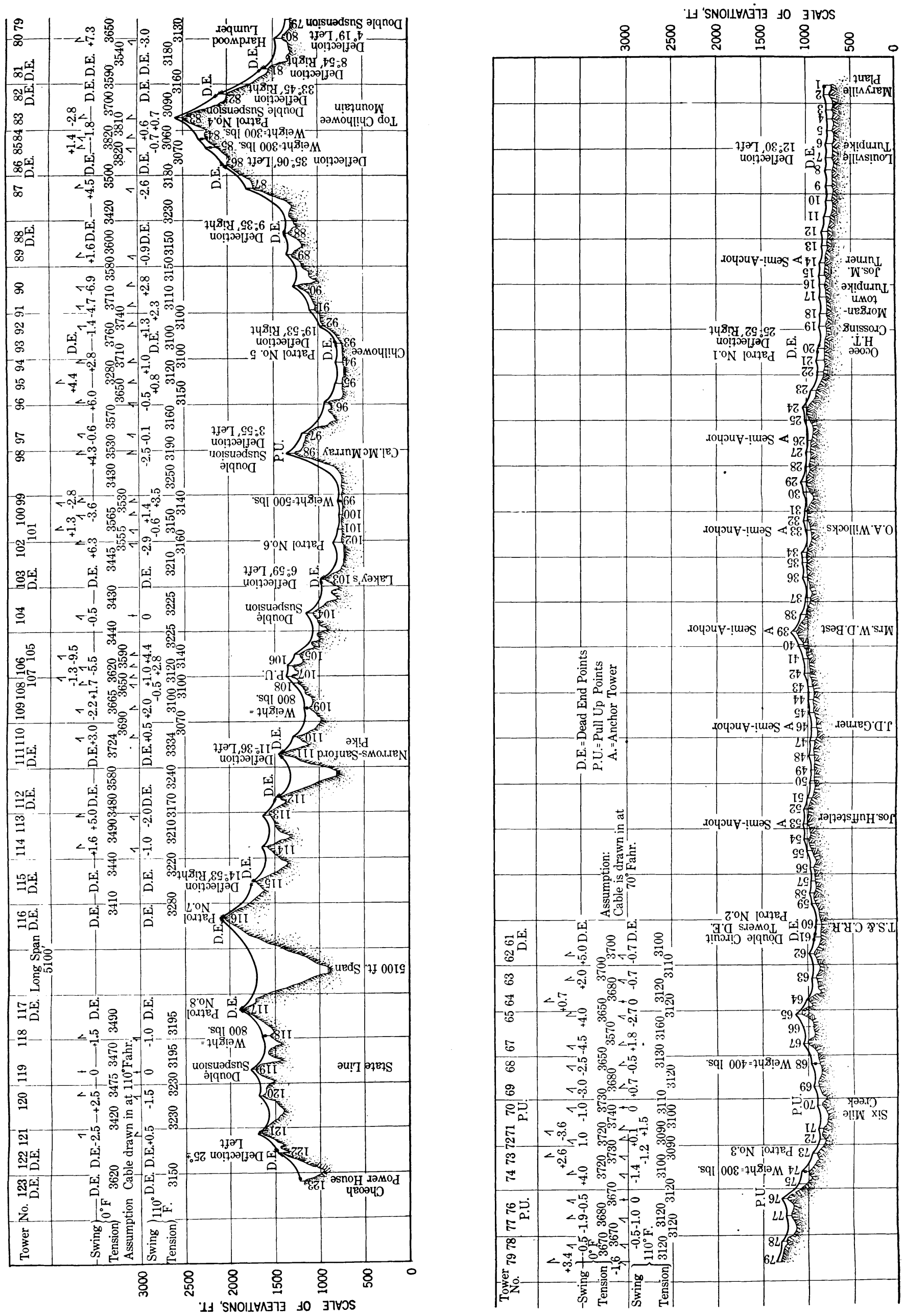

Profile of 150,000 -Volt Line 
remaining single circuit lines which will connect with the present plant at Cheoah. The right-of-way purchases include tree trimming rights fifty feet on each side and outside of the entire right-of-way. A telephone line on wood poles is provided for along each side of the right-of-way, one of which is at present completed.

The span lengths in the level country are fairly uniform and not over $800 \mathrm{ft}$., but in the mountains hardly any two spans are alike and several are over $2000 \mathrm{ft}$., while at one point where the line crosses the gorge of the Little Tennessee River, the span length is $5010 \mathrm{ft}$. The average span length for the entire line is more than $1200 \mathrm{ft}$.

The greatest altitude at any point in the line is about $2100 \mathrm{ft}$. and the corona is not, therefore, a serious item. However, on account of the high voltage, a considerable diameter for the conductor is desirable and it was furthermore necessary to use one having ample strength in order to meet the conditions imposed by the long spans and rough country. Accordingly, the conductor consists of aluminum reinforced with high grade steel which provides minimum weight with maximum strength. It was furthermore thought best to provide for carrying the entire load of the Cheoah power house on one line in case of emergency.

After the completion of the line and just before it was put into service in March, 1919, it was short-circuited at the powerhouse and current corresponding to 37$500 \mathrm{kw}$. and $75,000 \mathrm{kw}$. respectively, at 100 per cent power factor, was supplied at the receiving end from a steam turbine plant, with the following results.

\begin{tabular}{c|c|c|c|c|c}
\hline Amps. & Volts. & $\mathrm{Kw}$. & Frequency & $\begin{array}{c}\text { Power } \\
\text { Factor }\end{array}$ & $\begin{array}{c}\text { Line } \\
\text { loss }\end{array}$ \\
\hline 144 & 5160 & 330 & 60 & 25.6 & $0.885 \%$ of full load \\
\hline 288 & 9720 & 1230 & 60 & 25.4 & $1.65 \%$ of double load \\
\hline
\end{tabular}

Temperature air at power-house $18.0 \mathrm{deg}$. cent.

Temperature air at receiving end $13.5 \mathrm{deg}$. cent.

\section{HydRaUlic Plant}

The dam of the present development is of reinforced concrete approximately $500 \mathrm{ft}$. long on its up-stream face, extending across the rocky gorge in the Great Smoky Mountains, through which the Little Tennessee winds its way westward to join the Big Tennessee. The crest of the dam is approximately $177 \mathrm{ft}$. above normal tail-water elevation, while by means of Taintor gates the pool level can be raised about $15 \mathrm{ft}$.

A tunnel about $540 \mathrm{ft}$. long driven through the rock in the left bank of the stream, discharges into a surge tank, also excavated in the rock, from which four tunnels lead sharply downward to the turbines in the powerhouse.

\section{POWER House}

The power house which is constructed of reinforced concrete, approximately $216 \mathrm{ft}$. long, by $611 / 2 \mathrm{ft}$. wide inside, provides for four generating units, of which three are installed at the present time. These are of the vertical-shaft type operating at a normal speed of $1711 / 2$ rev. per min., and capable of delivering $20,000 \mathrm{kw}$. at 13,200 volts, three-phase, 60 cycles. Each feeds directly through a three-pole, 1200-ampere, automatic, inverse-time-limit, oil circuit breaker to a bank of three $7000-\mathrm{kv}$-a. single-phase, transformers stepping up to 150,000 volts. The high-tension side of these transformers are operated in star with neutral grounded and are connected to a high-tension bus, to which at present is connected through choke coils, one three-phase transmission line. Provision is made in the outgoing line for the future installation of a 150,000-volt oil cir-

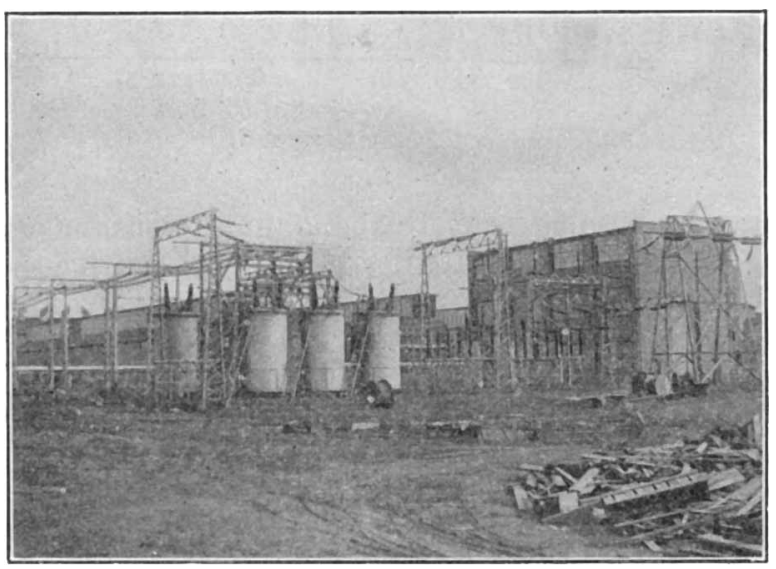

Receiving Station at Alcoa, Tenn.

cuit breaker. Electrolytic lightning arresters are provided, and arc suppressors equipped with eight automatic fuses per phase are being installed.

At Alcoa, the line connects directly through choke coils to a bank of three 14,000-kv-a. transformers, stepping down to 13,200 volts. Electrolytic lightning arresters are provided and provision is made for the future installation of an automatic oil circuit breaker on the line side. The low-tension side is connected through disconnecting switches and a 3000-ampere automatic oil circuit breaker to a 13,200-volt bus system to which are connected through disconnecting switches, oil breakers and transformers, twenty $2500-\mathrm{kw}$. synchronous converters. These converters deliver 500 volts d-c. to a 24-hour electrolytic load.

\section{TRANSMission Line}

The conductor decided upon is a 500,000-cir. mil aluminum cable, steel reinforced, the details of which are given with other data at the eud of this paper. The maximum tension in the conductor was not taken at the full elastic limit, but at 8000 pounds for the reason that in previous installations of somewhat similar character it had been found that greater tensions re- 
quired a greater cost for tower construction and a preliminary investigation in the present case indicated this tension to be sufficient. ice or wind was computed. This gave a value of approximately 3300 pounds. From this value the unloaded tensions for every 20 degrees from 0 to 110 were

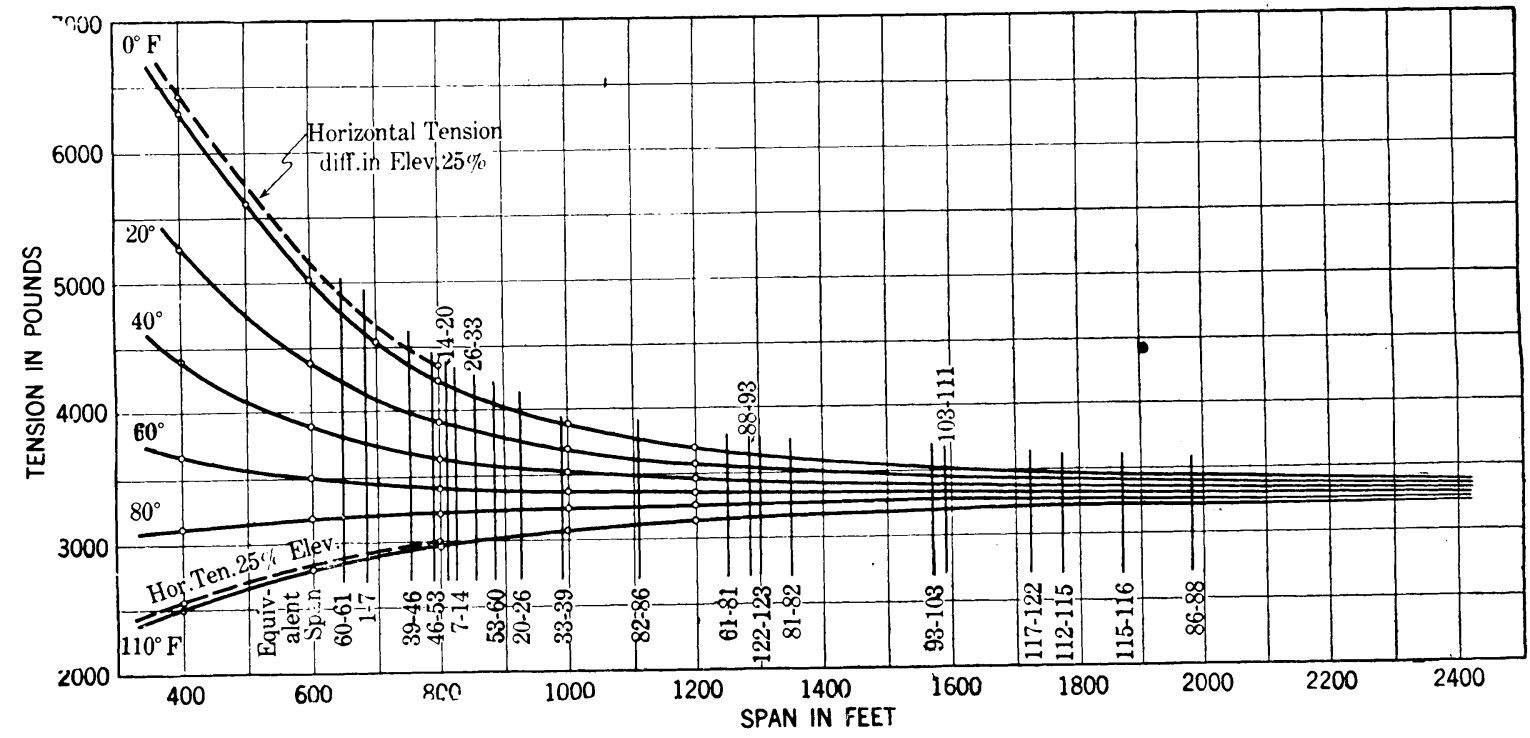

Conductor Stringing Curves

It was assumed that this maximum tension would occur at 0 deg. fahr. with one-half inch of ice all around the conductor and a wind pressure of six pounds per square foot of projected surface of ice-covered cable.

By carefully studying the profile of the land the dead end and semi-anchor towers were located in such manner that the equivalent values of the spans between any

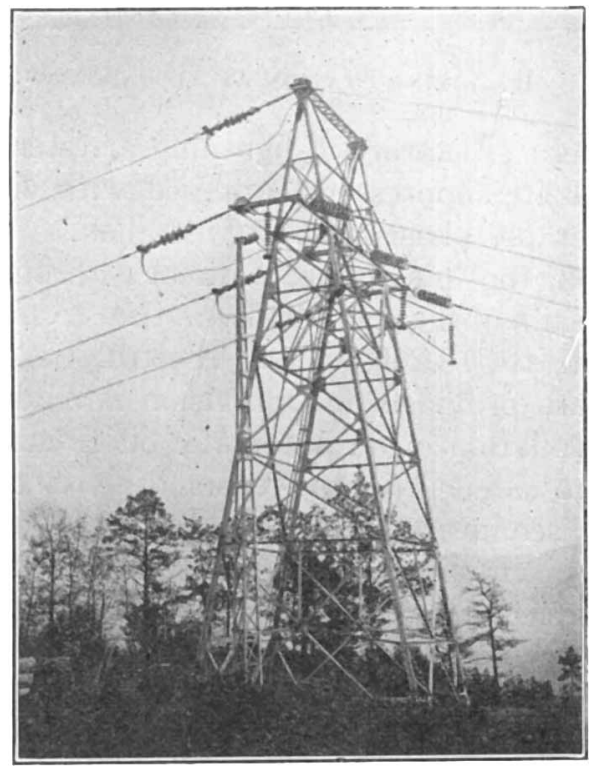

Long Span Anchor Tower

two anchor points, as referred to level supports, would not be very widely different. By this means the shortest equivalent span was found to be $650 \mathrm{ft}$. and the longest (exclusive of the $5010-\mathrm{ft}$. span which was treated separately) $2400 \mathrm{ft}$.

From the condition of maximum load in the shortest span, the tension corresponding to $70 \mathrm{deg}$. fahr, without calculated for the ruling equivalent span for each of the consecutive dead end sections of the line. These curves are given in one of the illustrations. The equivalent

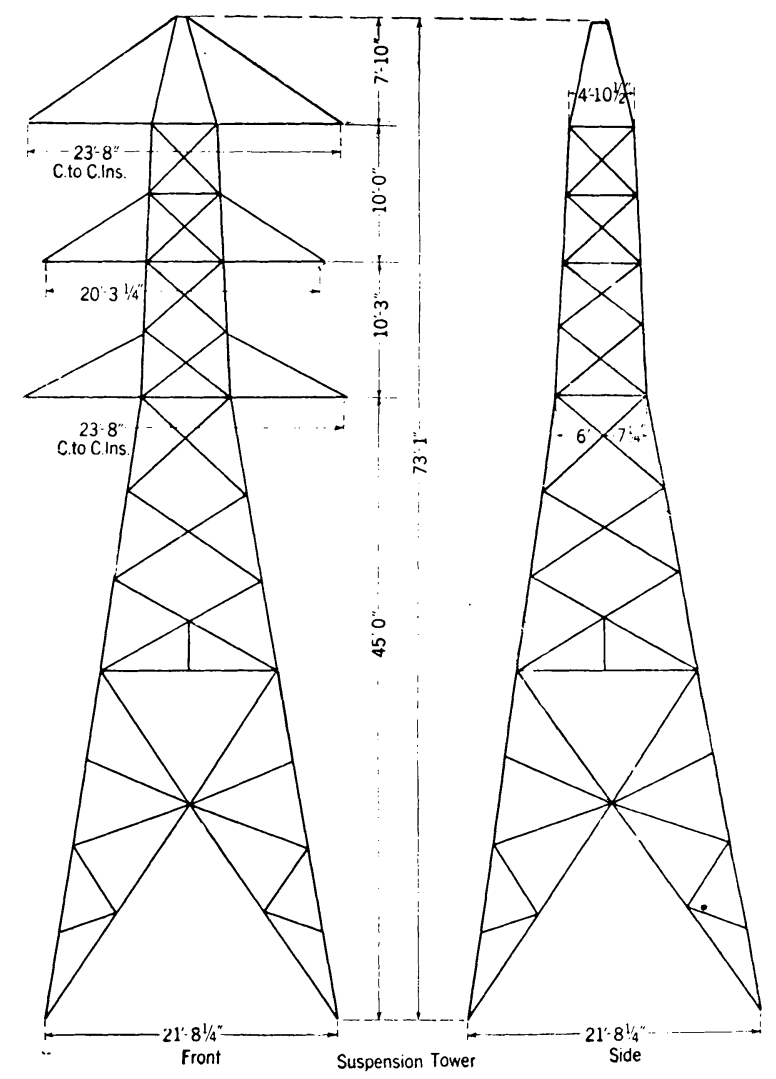

span numbers refer to the tower numbers in the profile, which is also illustrated.

The cable was strung out through travelers and pulled up to the tension given in the curves corresponding to the stringing temperature. The insulator strings 


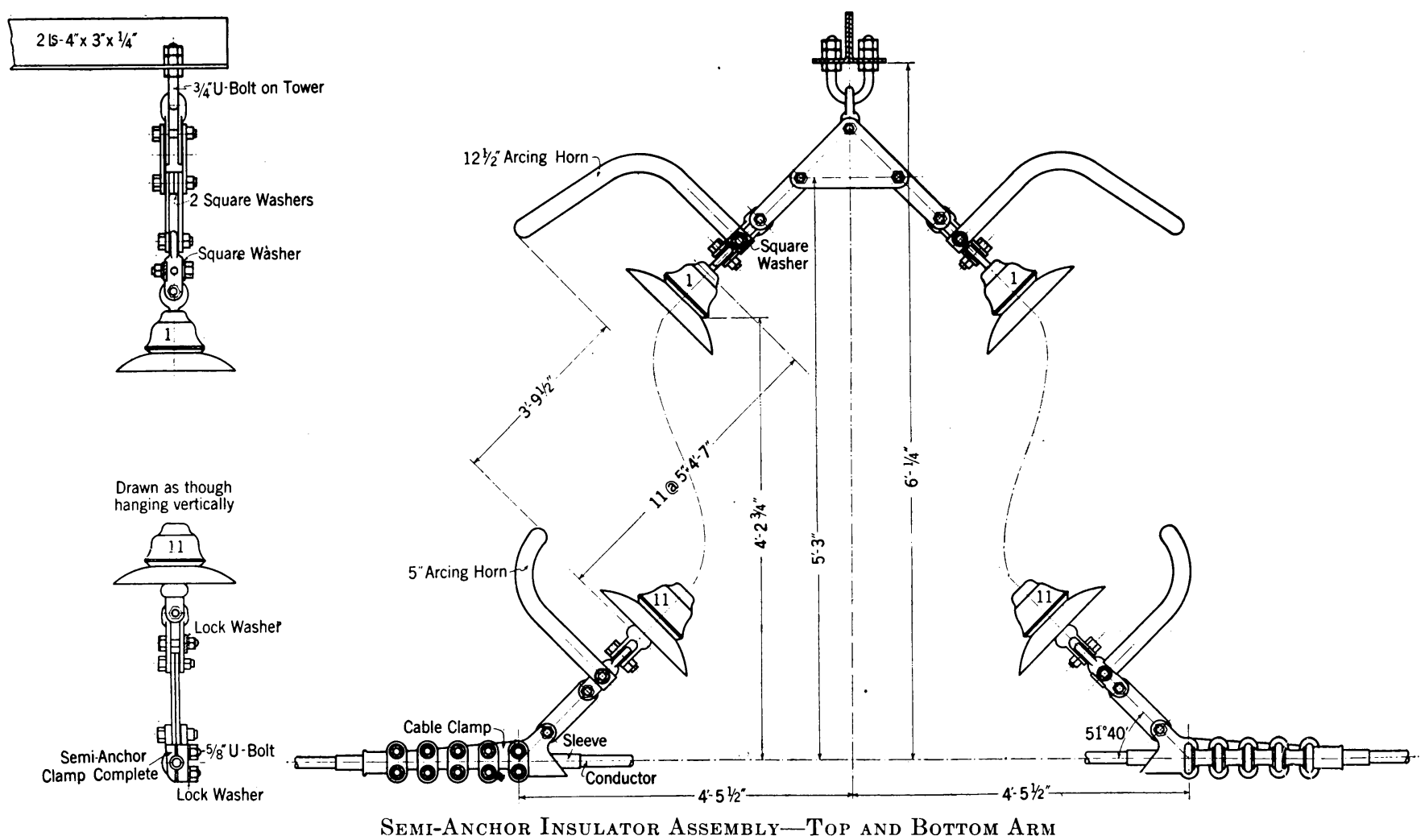

were hung vertically under these conditions but as the adjacent equivalent spans in each anchor section were not equal, any temperature changes produces a swing from the vertical in the insulator strings. A study was made of this condition and the position of the insulators was calculated for $0 \mathrm{deg}$. and $110 \mathrm{deg}$. fahr. The profile indicates the right and left swing of the insulators at the various towers in the rough country, correspond- ing to those extreme tempratures, assuming the strings to be vertical at $70 \mathrm{deg}$. fahr.

The towers were constructed of galvanized steel, delivered on the ground in sections and bolted together. As stated above the towers in the level country were double-circuited and in the mountains single. The illustrations indicate the several types of towers, together with the extensions used on rough ground as

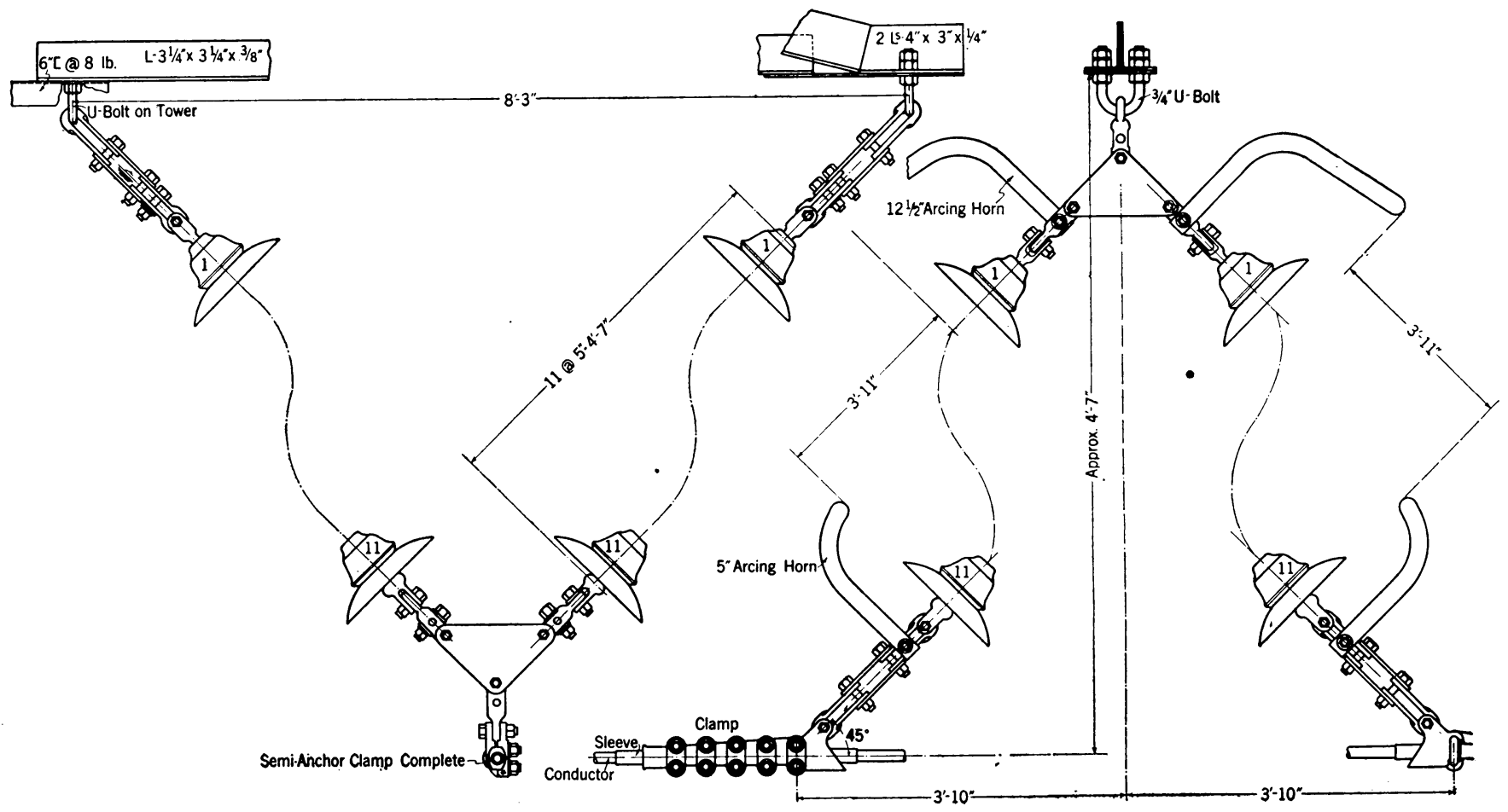

Semi-Anchor Insulator-Middle Arm 
well as the anchors. The approximate weight of a double circuit suspension tower is 12,900 pounds and that of an anchor tower 13,200 pounds. The single circuit suspension tower weighs 11,200 pounds and the anchor tower 13,100 pounds.

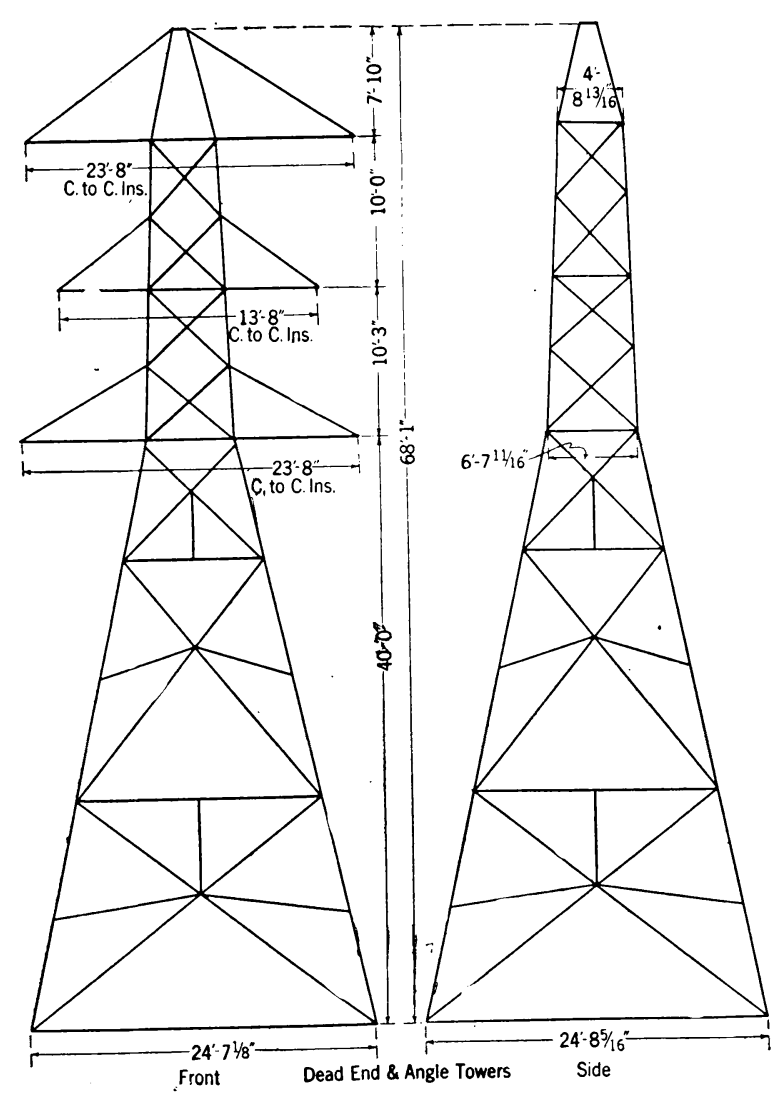

Calculations were made of the side sway assuming wind pressures of 19 pounds per square foot on bare cables, and in order to provide proper clearance from the tower arms, brackets were provided to which the insulator strings are attached. These brackets, which

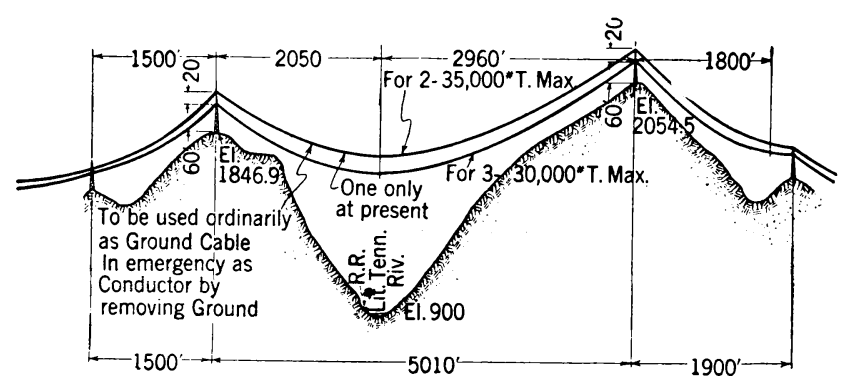

Elevations at Long Span

appear in the illustration, were hinged so as to prevent applying excessive torsional stresses to the bracket arms in case of a broken conductor.

In addition at certain points where towers are located on side hills, the cable weight on the suspension strings is reduced in cold weather. While actual uplifts are provided against at these points, the tendency for side swing is increased and to overcome this, weights were attached to the insulator strings. This construction is shown in the illustrations and the towers where this construction was used are indicated on the profile.

Where the weight of unusually long spans has to be carried by suspension insulators the strings are doubled,

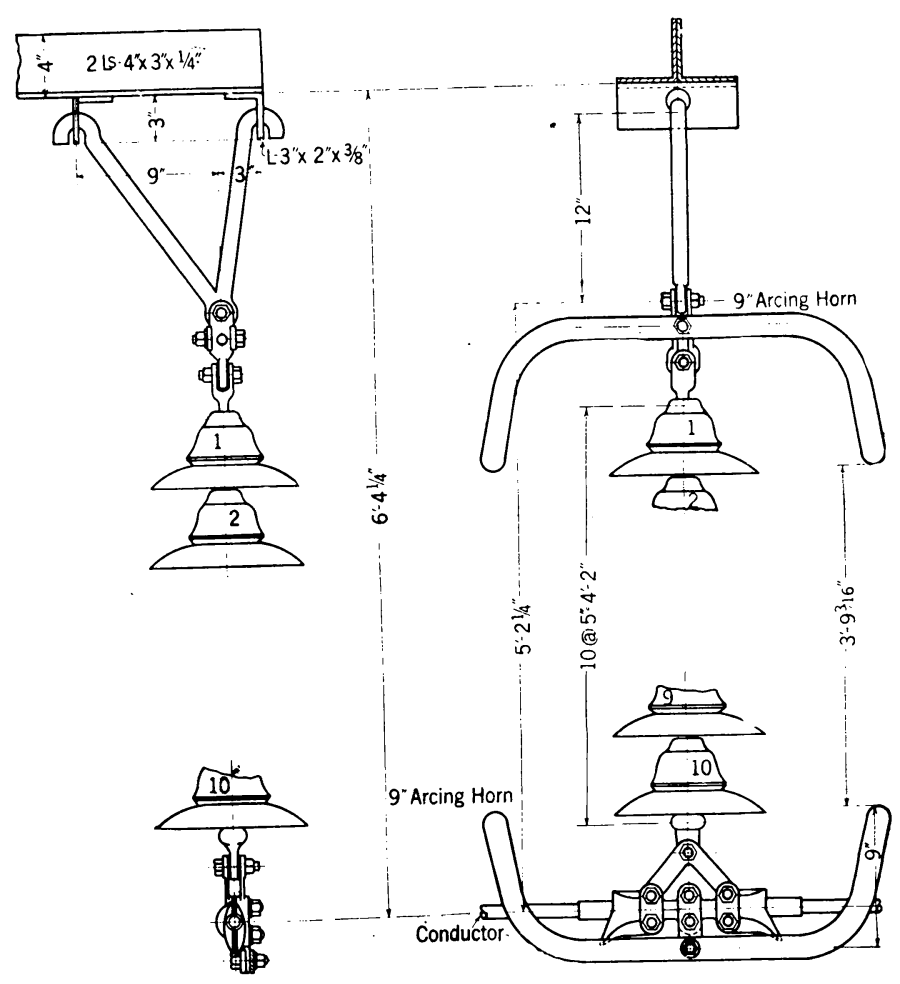

Suspension Insulator Assembly

Top and bottom arm, two-circuit tower; all supports. one-circuit tower

while on the middle arms of the double-circuit towers double strings of insulators are used to prevent side sway and to enable a short arm to be used. This arrangement obviated placing all three phases in a vertical plane and enabled the bracing members of the

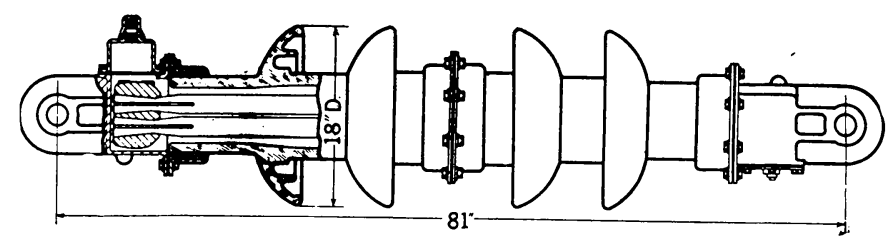

Strain Insulator at Long Span

tower to be reduced in weight, while still providing ample strength to resist torsional stresses due to a broken conductor.

At present one ground wire consisting of a $1 / 2$-in. galvanized, high-strength, stranded steel cable is provided throughout the line except at the long span where special arrangement is provided as described later. Provision is made on the towers for adding a second ground wire if desired. The stringing tension for the ground wire was 2700 pounds at $70 \mathrm{deg}$. fahr.

One of the illustrations shows the relative elevation of the supports for the long span, compared to its length. The horizontal distance between supports is $5010 \mathrm{ft}$. while the difference in elevation is $208.5 \mathrm{ft}$. 
The temperature at the time of stringing the cables was about $80 \mathrm{deg}$. fahr. and the three lower cables were strung with a sag of $237 \mathrm{ft}$. below the lower support, corresponding to a tension of 19,000 pounds per cable. The upper cable was installed with a sag of $216 \mathrm{ft}$. below its lower support and with a tension of 20,400 pounds. The horizontal separation between the lower conductors is $20 \mathrm{ft}$. and the upper cable is $20 \mathrm{ft}$. above the lower three at the points of support.

One of the long span towers, marked $W$ in the illustration weighs 55,000 pounds and the other $W W$ weighs 57,000 pounds.

In these spans the steel core of each cable carries the entire load and the cores are socketed with zinc into open forged steel bridge sockets which are attached directly to the strain insulators. The aluminum part of the cable is cut off in advance of the sockets and connection is made by means of an aluminum parallel groove clamp and jumper connection to the other side of the tower.

Each cable is provided at each tower with a single 150,000-volt, oil filled, porcelain covered, wood strain insulator. In deciding to use this type of insulator the engineers were guided by the previous satisfactory performance of similar insulators on a 110,000-volt river crossing belonging to the Tennessee Power Company. Very careful and complete tests were made of the insulators before installing, and in order to provide a spare part in case of a strain insulator breakdown the upper conductor of the long span was arranged to be normally grounded, thus replacing the standard ground wire. A busbar arrangement is provided so that this conductor may be substituted for anyone of the three conductors, which may then be grounded and repaired. One of the cuts illustrates the construction of the strain insulators.

This span, which is understood to be at present the longest single conductor span in the world, involved cable lengths too heavy to be readily transported to either tower and consequently a rather ingenious scheme was employed for installing them. They were wound at the factory on special reels having a partition which divided the total amount of the cable into two parts, each of proper length to reach from the railroad at the bottom of the gorge to one of the towers.

The reel was set up beside the railroad track and a portion of the long section pulled out first. When the portion of this section still remaining on the reel equalled the short section, the latter was started out. The ends arrived at the towers at the same time and the loop was removed from the partition in the reel without damage or splicing. The cables were pulled to tension with a donkey engine.

There are eight patrol stations provided along the telephone line on the right of way. The location of each is indicated on the profile. Two patrolmen are constantly employed. One covers the line from Alcoa to Patrol Station No. 4 at Tower No. 83, while the

other inspects the line from Tower No. 83 to the Cheoah Power House.

The latter covers the rough country from Cheoah to Patrol Station No. 7 at Tower No. 111 on foot and over the balance of the distance to Tower No. 83 he rides horse-back. Each patrolman goes over the line once every week and in addition makes an inspection after any storm or lightning interference.

\section{CONDUCTOR}

The conductor consists of aluminum cable steel reinforced composed of a double galvanized extra high strength steel core, overlaid with strands of hard drawn aluminum.

The elastic limit and ultimate strength of the aluminum strands are respectively 14,000 and 24,000 pounds per square inch.

The corresponding values for the steel core are 130,000 and 160,000 pounds per square inch. The elastic limit and ultimate strength of the complete cable is taken as the sum of the corresponding values for the individual strands.

The modulus of elasticity of the aluminum portion of the cable is taken at $9,000,000$ pounds per square inch and of the steel portion $30,000,000$ pounds per square inch.

The characteristics of the conductors are as follows:

\section{Standard Conductor}

Steel

Aluminum.

Diameter complete cable. ..........

Weight per foot complete cable.......

Elastic limit complete cable..........

Ultimate strength complete cable......

Weight of ice per foot ( $1 / 2$ in. thick)...

Wind pressure per foot $(6 \mathrm{lb}$. square $\mathrm{ft}$. over ice)

Resultant, loaded weight per foot.....

Wind pressure per foot (19 lb. square $\mathrm{ft}$. on bare cable)...............

Resultant, loaded, weight per foot..... Virtual coefficient of expansion per deg.

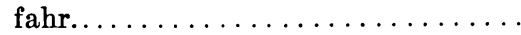
Virtual modulus of elasticity....... Long Span Conductor

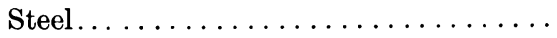

Aluminum. . . . . . . . . . . . . . .

Diameter complete cable...........

Weight per foot complete cable....... Elastic limit complete cable... . . . . . . Elastic limit steel portion........... Ultimate strength complete cable...... Ultimate strength steel portion....... Weight of ice per foot ( $1 / 2$ in. thick)... Wind pressure per foot $(6 \mathrm{lb}$. sq. ft. over ice) . . . . . . . . . . . . . Resultant, loaded weight per foot..... Wind pressure per foot (19 lb. sq. ft. on bare cable $). . . \ldots \ldots \ldots \ldots \ldots \ldots$ Resultant, loaded, weight per foot..... Virtual coefficient of expansion per deg. fahr................... Virtual modulus of elasticity........
$19 \times 0.0775$ in $30 \times 0.1291 \mathrm{in}$

0.904 in.

$0.776 \mathrm{lb}$.

$17140 \quad \mathrm{lb}$

$23750 \quad \mathrm{lb}$.

$0.859 \mathrm{lb}$.

$0.952 \mathrm{lb}$.

$1.892 \mathrm{lb}$.

$1.43 \mathrm{lb}$

$1.625 \mathrm{lb}$.

0.00001003

$12,900,000 \quad \mathrm{lb}$.

$61 \times 0.097$ in.

$22 \times 0.150$ in.

1.175 in.

$2.032 \mathrm{lb}$.

$65,000 \quad \mathrm{lb}$.

$59,000 \mathrm{lb}$.

$82,000 \mathrm{lb}$

$73,000 \quad \mathrm{lb}$

$1.025 \mathrm{lb}$

$1.085 \mathrm{lb}$

$3.25 \mathrm{lb}$.

$1.86 \mathrm{lb}$.

$2.75 \mathrm{lb}$.

0.0000077

$20,200,000$ 


\section{INSULATORS}

It was realized that carefully selected porcelain with working mechanical tensions limited to safe values would be necessary to insure successful operation and, accordingly, the following points were covered by the specifications when the standard suspension and anchor insulator units were purchased:

Porcelain bodies to be non-absorbent, thoroughly vitrified, free from cracks, etc., and surfaces in contact with cement to be unglazed.

Caps to be of galvanized malleable iron of minimum ultimate strength of 30,000 pounds per square inch and designed for a maximum stress of 12,000 pounds per square inch at 9500 pounds total load.

Pins to be of soft steel drop forgings designed for a maximum stress of 35,000 pounds per square inch at 9500 pounds total load.

Parts to be cemented together with slow setting neat Portland cement of best quality.

Porcelain parts taken from kiln to be subjected to dry flashover test for five minutes. Five days after cementing and before six days, units to be subjected to 3500 pounds load for five minutes. Units to show puncture voltage under oil of at least 120 per cent of dry flash-over voltage. Ultimate tensile strength of complete unit to be not less than 8500 pounds. Resistance of units to be infinite when tested with 1000-volt, 2000 megohm megger. Standard A. I. E. E. wet flash-over test for complete string of ten units to be not less than 390,000 volts at 60 cycles.

For the. long span strain insulators the following points were covered by the specifications;

Tension members to consist of selected hickory and be able to stand before assembly a tension test of 25,000 pounds for onehalf minute, also a dry flash-over test of 520,000 volts.

End castings before assembly to be able to stand a load of 75,000 pounds.

Complete insulator to stand load of 35,000 pounds for onehalf minute, a temperature of 140 degrees fahrenheit for five hours without leakage of oil and after cooling a test of 520,000 volts.

Power was first turned on this line April 16th, 1919, and to date (February 1920) no interruptions due to any defects of the line have occurred.

The writer is indebted to Messrs. William Hoopes, T. J. Bostwick, I. G. Calderwood, L. W. Henry and B. F. Grote for the data included in this paper.

\section{ARMY PAY BILL AFFECTS SOME CIVILIAN ENGINEERS}

When the Army Pay Bill was made law, it carried a provision whereby some of the officers of the Coast \& Geodetic Survey are to receive the same pay and allowance as prescribed for officers of the Navy with whom they hold relative rank, as prescribed under act of May 22, 1917, the provisions of which were made to apply to officers of the Coast and Geodetic Survey. The bill which recently became law provides for the personnel of the Army, Navy, Marine Corps, Coast \& Geodetic Survey, Public Health Service and the Coast Guard.

Actual increase in compensation ranges from about $\$ 720$ to $\$ 2,700$ in the various grades, which includes all the allowances granted by the bill. The officers in the Coast \& Geodetic Survey feel that this is a remarkable recognition of civil engineers of the Government, and it is contemplated that it will enable them to fill up many vacant positions in that service, as a result of which, they will be able to more nearly carry out their program in the development of magnetic surveys, traverse and leveling, precise and secondary triangulation. In this connection it is interesting to note that about forty vacancies now exist in the lower grades in the officered personnel, due to the fact that civil en- gineering graduates have not been attracted by the old pay. The entrance salary will now be slightly in excess of $\$ 2000$, which will attract more civil engineering graduates to this service.

- In addition to the possibility of improved conditions in personnel of the Coast and Geodetic Survey, it is probable that the Sundry Civil Bill has passed by the House will finally contain an item for magnetic and geodetic surveys in Alaska appropriating $\$ 147,000$. About $\$ 28,000$ of this sum will be devoted to the magnetic surveys of the country and the balance will be expended on precise and secondary triangulation, traverse and leveling. This appropriation is the same as was available for the fiscal year 1920, except that last year's appropriation was made up of a regular appropriation of $\$ 100,000$ plus a deficiency appropriation of $\$ 47,100$. This compares with $\$ 90,000$ available in 1919, and represents an increase of 63 per cent over the period of two years. Officers of the Coast and Geodetic Survey have expressed the opinion, however, that even with this substantial increase, there is not as much money available as will be needed in order to carry the control surveys well ahead of the detailed topographic mapping program. 